\title{
Ending lethal discrimination against people with serious mental illness
}

Holly Taggart and Sue Bailey

\section{Summary}

Each year in England 33000 people diagnosed with a serious mental illness (SMI) die from causes that could have been avoided. Our mental-health-specific Atlas of Variation is the first to demonstrate the extent to which these inequalities and inequities affect mortality nationally.

\section{Declaration of interest}

H.T. is author of the Atlas of Variation to which S.B. contributed the Foreword.

\section{Copyright and usage}

(c) The Royal College of Psychiatrists 2015.
Holly Taggart (pictured) is a policy analyst at the Royal College of Psychiatrists and a registered mental health nurse. Professor Dame Sue Bailey is Chair of the Academy of Medical Royal Colleges, immediate past-President of the Royal College of Psychiatrists and a consultant child and adolescent forensic psychiatirst at the Greater Manchester West NHS Foundation Trust.

\section{Background}

In 2011 the cross-party government published its implementation strategy for No Health Without Mental Health, including six shared objectives. ${ }^{1}$ One of these objectives called for fewer people with mental health problems to have poor physical health, fewer people to die prematurely and fewer people with physical ill health to have mental health problems. Three years on, the Department of Health published a report, Living Well for Longer, calling for a reduction in avoidable premature mortality. ${ }^{2}$ This is pertinent, as two-thirds of all deaths in those aged under 75 in England remain avoidable (50000 deaths are preventable, 19000 deaths are amenable to healthcare and 30000 deaths are both preventable and amenable). A third of avoidable deaths are in people with serious mental illnesses (SMI). ${ }^{2}$

Yet despite these policy initiatives it has been known for many years that people living with SMI can die between 15 and 20 years younger than the general population. Although these figures are useful in identifying the overall mortality gap at a national level, it is not possible to infer whether these poor outcomes apply equally to people with SMI across the country. The first mental-health-specific Atlas of Variation for England aimed to address this by presenting relevant life-course data by region. ${ }^{3}$

\section{Variations in excess mortality}

Through policy developments more recently, the Health and Social Care Information Centre has started to publish data on 'excess under 75 mortality for people in contact with secondary mental health services' through a standardised mortality ratio (SMR). This is calculated through an extended analysis of linked data from the mental health minimum data set to Office of National Statistics deaths data. For the first time it is now possible to track excess mortality - or premature death - over time, gender, age group and, importantly, by region. The data reveal that people in contact with secondary mental health services in England have an SMR of 3.47, meaning they are 3.47 times more likely to die prematurely than those without SMI. ${ }^{4}$ Worse still, average excess mortality figures have been increasing each year. There are also marked differences between age groups. Those aged 30-34 years old have the greatest risk of excess death, and this is increasing. Likewise in those aged 60-64, excess death is now at its highest since data collection began. It is also apparent that the natural gender differences in overall mortality do not apply to excess mortality, as the differences between SMR in men and women with SMI are marginal.

Although some of these figures are in line with what is already known, recent data relating to the regional variation in the SMR are more telling. People living in Hartlepool have the highest rates of excess death in England with an SMR of 5.64, whereas people living in the Isle of Wight have the lowest rates of excess death with an SMR of 1.39. Therefore, if you have SMI and live in Hartlepool, you are 4.25 times more likely to die prematurely than those living in the Isle of Wight.

Several factors may contribute to this variation but these figures tell a story of inequality and inequity. However, local areas are not powerless to change. In 1 year Newcastle upon Tyne saw the greatest improvement in reducing excess mortality compared with the rest of the country, whereas Swindon has seen the greatest deterioration.

This is a global issue. Across other high-income countries, all but one area (District of Colombia, USA) has an increased risk of excess death in people with SMI. England ranks worse than Korea, Slovenia, Denmark and all American states (Table 1). ${ }^{4-6}$

How can we explain the reason why people living with SMI in high-income countries are more likely to die prematurely? Thornicroft noted that people with a SMI have a higher occurrence of risk factors for many chronic diseases, the iatrogenic effects of some psychiatric medications as well as higher rates of suicide, accidental and violent death, all of which contribute to poor physical health. ${ }^{7}$ Although the contribution of suicide and accidental death is significant in increasing the overall mortality rate, it is the higher occurrence of risk factors for chronic diseases, such as smoking, poor diet and a lack of exercise, which has the greatest impact on SMR. Our Atlas of Variation draws attention to this fundamental issue: people with SMI have poorer access to physical healthcare compared with the general population. ${ }^{3}$

An example of this is that people with mental illnesses represent $42 \%$ of the adult population who smoke tobacco, compared with $20 \%$ in the general population. These rates vary by mental disorder: of those who smoke $27 \%$ of people have a common mental disorder: $40 \%$ have psychosis, $46 \%$ have an alcohol dependency, $60 \%$ have a drug dependency; and 70\% of former in-patients smoke. ${ }^{8}$ Elevated rates of smoking are not confined to the adult population. Of the $5 \%$ of $11-16$ year olds who smoke, $30 \%$ have conduct disorder, $19 \%$ have an emotional 


\begin{tabular}{|c|c|c|c|}
\hline \multirow[b]{2}{*}{ State/country } & \multicolumn{3}{|c|}{ Standardised mortality ratio (SMR) } \\
\hline & Overall & Schizophrenia & $\begin{array}{l}\text { Bipolar } \\
\text { affective } \\
\text { disorder }\end{array}$ \\
\hline District of Colombia, USA & 0.6 & - & - \\
\hline Virginia, USA & 1.2 & - & - \\
\hline Rhode Island, USA & 1.5 & - & - \\
\hline Texas, USA & 1.6 & - & - \\
\hline Arizona, USA & 2.2 & - & - \\
\hline Missouri, USA & 2.2 & - & - \\
\hline Utah, USA & 2.2 & - & - \\
\hline Oklahoma, USA & 2.9 & - & - \\
\hline Denmark & 3.1 & 4.1 & 2.1 \\
\hline Slovenia & 3.2 & 3.8 & 2.5 \\
\hline Vermont, USA & 3.2 & - & - \\
\hline Korea & 3.4 & 3.6 & 3.1 \\
\hline England & 3.5 & - & - \\
\hline Finland & 5.0 & 6.0 & 4.0 \\
\hline Israel & 5.1 & 6.8 & 3.3 \\
\hline New Zealand & 5.2 & 5.9 & 4.5 \\
\hline Sweden & 6.1 & 8.8 & 3.3 \\
\hline \multicolumn{4}{|c|}{$\begin{array}{l}\text { a. Sources of data: for all US states from Lutterman et al }(2003))^{5} \text { for England from } \\
\text { the Health \& Social Care IIformation Centre }(2015)^{4}{ }^{4} \text { and for all other countries from } \\
\text { the Organisation for Economic and Co-operative Development (2013). }\end{array}$} \\
\hline
\end{tabular}

disorder and 15\% have attention-deficit hyperactivity disorder. ${ }^{9}$ Despite this, the evidence suggests that many people with mental illnesses want to quit smoking and can do so in a supportive environment. However, health promotion is not routinely provided to people with mental illnesses and only a minority of people ever receive cessation pharmacotherapy.

Similarly, in terms of preventive healthcare, the evidence suggests that $88 \%$ of people with mental illnesses are not screened for dyslipidaemia, up to $62 \%$ have untreated hypertension and are far less likely to have their cholesterol monitored. Furthermore, the National Institute for Health and Care Excellence (NICE) recommend that individuals with schizophrenia receive a physical health check each year, yet the National Audit of Schizophrenia found that $71 \%$ of those living with the illness never receive this. ${ }^{10}$ As a result, people with mental illnesses have higher rates of diabetes, obesity, cardiovascular and gastrointestinal disorders, HIV and chronic and acute pulmonary disease. ${ }^{11}$

This discriminatory practice also extends to emergency care. People with mental illnesses are less likely to receive specialised interventions, such as stenting and coronary artery bypass grafting, when presenting with cardiac problems.

As a consequence of these risk factors, coupled with the varying levels of access to good-quality primary, secondary and tertiary preventive healthcare, people with a SMI are 4.7 times more likely to die from liver disease, 4.6 times more likely to die from respiratory disease, 3.2 times more likely to die from cardiovascular disease and 1.7 times more likely to die from cancer, than the general population.

Both Thornicroft ${ }^{12}$ and the charity, Rethink Mental Illness ${ }^{13}$ described this as lethal discrimination. These findings certainly appear to reflect this, not just in England but also across other high-income countries. There is also emerging evidence of even greater premature mortality for people living with SMI in low-income countries.

\section{Conclusions}

Wahlbeck et al state that the relative life expectancy of people with SMI is a proxy measure for the effectiveness of social policy and health service provision. ${ }^{14}$ Therefore, as the National Health Service in the UK faces the major challenge of delivering value at low costs; reducing unwarranted variation in outcomes, quality and safety; and working to prevent disease in our health and social care system, we must focus on reducing the mortality gap through equity of access to all levels of healthcare, including acute care, preventative medicine and health promotion. In 1998, Harris \& Barraclough noted that people with mental illnesses have not received the benefits of improved health outcomes and improved healthcare delivery in line with the rest of the population. ${ }^{15}$ Certainly, 17 years on this is still the case.

Holly Taggart, MNurSci, RMN, MSC, Royal College of Psychiatrists, London; Sue Bailey, MBChB, FRCPsych, Academy of Medical Royal Colleges, London, UK

Correspondence: Holly Taggart, Policy Unit, Royal College of Psychiatrists, 21 Prescot Street, London E1 8BB, UK. Email: htaggart@rcpsych.ac.uk

First received 1 Apr 2015, final revision 12 Jul 2015, accepted 19 Aug 2015

\section{References}

1 Department of Health. No Health without Mental Health: A Cross Government Mental Health Outcomes Strategy for People of all Ages. Department of Health, 2011.

2 Department of Health. Living Well for Longer. National Support for Local Action to Reduce Premature Avoidable Mortality. Department of Health, 2013.

3 Taggart, H. The CentreForum Atlas of Variation: Identifying Unwarranted Variation across Mental Health and Wellbeing Indicators. CentreForum, 2014.

4 Health \& Social Care Information Centre. Dataset 1.5.i Excess under 75 mortality rate in adults with serious mental illness (formerly indicator 1.5). Health \& Social Care Information Centre, 2015

5 Lutterman T, Ganju V, Schacht L, Shaw R, Monihan K, Bottger R, et al. Sixteen State Study on Mental Health Performance Measures. DHHS Publication No. (SMA) 03-3835. Center for Mental Health Services, Substance Abuse and Mental Health Services Administration, 2003.

6 Organisation for Economic and Co-operative Development. Health at a Glance. OECD, 2013.

7 Thornicroft G. Physical health disparities and mental illness. Br J Psychiatry 2011; 199: 441-2.

8 McManus S, Meltzer $\mathrm{H}$, Campion J. Cigarette smoking and mental health in England. Data from the Adult Psychiatric Morbidity Survey. National Centre for Social Research, 2010.

9 Green H, McGinnity A, Meltzer H, Ford T, Goodman, R. Mental health of children and young people Great Britain 2004. Office for National Statistics, 2004.

10 Royal College of Psychiatrists. Report of the National Audit of Schizophrenia (NAS) 2012. Healthcare Quality Improvement Partnership, 2012.

11 De Hert M, Correll CU, Bobes J, Cetkovich-Bakmas M, Cohen D, Asai, I. Physical illness in patients with severe mental disorders. I. Prevalence, impact of medications and disparities in health care. World Psychiatry 2011; 10: $52-77$.

12 Thornicroft G. Premature death among people with mental illness. BMJ 2013; 346: f2969.

13 Rethink Mental IIIness. Lethal Discrimination. Rethink Mental IIIness, 2013 (https://www.rethink.org/media/810988/Rethink\%20Mental\%20lllness\%20-\%20Lethal\%20Discrimination.pdf).

14 Wahlbeck K, Westman J, Nordentoft M, Gissler M, Munk Laursen T. Outcomes of Nordic mental health systems: life expectancy of patients with mental disorders. Br J Psychiatry 2011; 199: 453-8.

15 Harris EC, Barraclough B. Excess mortality of mental disorder. Br J Psychiatry 1998; 173: 11-53. 